like to agree with the Editor's suggestion ${ }^{3}$ that a belief in the importance of the brain marks us out as Cavaliers, we fear that the neuroscientific enterprise, marked by slow, painstaking data collection, hypothesis testing and incremental advances does not quite suit his analogy. Nor do we, in championing neuroscience, dismiss the importance of other levels of explanation as some of our respondents suggest. Our original editorial was clear on this. As for the suggestion that neuroscience is a form of behaviourism and must thereby deny the mind, we do hope that a brief survey of the past decade's cognitive neuroscientific literature refutes that concern.

McQueen is right to take us to task for forgetting emotion: this is an oversight in our article but not, we are happy to say, in the field, where affective and social neurosciences thrive. Blewett is also correct when he points out that major impacts on the lives of patients have arisen and continue to flow from phenomena that are meaningless when conceived solely within a neuroscientific framework.

We certainly do not demur from a biopsychosocial formulation; these are the three primary colours in which we paint our discipline and which make it more vibrant than other medical specialties. Rather, we point out that the 'bio-' aspect of psychiatry is getting brighter, stronger and, in our opinion, more useful such that, as a profession, we cannot afford to ignore it lest we do a disservice to our patients. To argue, as does Datta, that if we embrace this change then we shall be taken over by neurology is surely, as Johansson indicates, unfalteringly absurd.

After all, patients need good doctors first and foremost, and we believe that Reil conceived psychiatry as a broad discipline reflecting his own polymathematical abilities.

When we manage someone's arachnophobia with an appropriately eclectic mix of graded exposure, a selective serotonin reuptake inhibitor for comorbid depression, psychoeducation and family support we do not aim for them to live in a world populated by tarantulas, let alone become one. So, too, for psychiatry: in pointing out its neurophobic tendencies we aim to restore good function and allow it to move on. To us, this doesn't appear to be rocket science, just neuroscience.

1 Bullmore $\mathrm{E}$, Fletcher $\mathrm{P}$, Jones $\mathrm{PB}$. Why psychiatry can't afford to be neurophobic. Br J Psychiatry 2009; 194: 293-5.

2 Craddock N, Antebi D, Attenburrow M-J, Bailey A, Carson A, Cowen $\mathrm{P}$, et al. Wake-up call for British psychiatry. Br J Psychiatry 2008; 193: 6-9.

3 Tyrer P. From the Editor's desk. Br J Psychiatry 2009; 194: 386.

Peter B. Jones, University of Cambridge, Department of Psychiatry, Addenbrooke's Hospital, Cambridge CB2 2QQ, UK. Email: pbj21@cam.ac.uk; Ed Bullmore, Paul Fletcher, University of Cambridge, Department of Psychiatry, Addenbrooke's Fletcher, University
Hospital, Cambridge

doi: 10.1192/bjp.195.3.269a

\section{Psychopathic traits and studies of deception}

Fullam et als aim was 'to investigate the relationship between neural responses during deception and psychopathic personality traits. ${ }^{1}$ One of my main concerns is that what the authors referred to as 'deception' was not actually deception. The study participants were aware that the truth was known and they were being asked to 'lie' for the study. I do not believe this to be a good enough surrogate for deception.

For the purpose of the study, the word 'lie' was defined as 'the intentional giving of a false response and awareness that the response is false rather than a mistake'. I believe this definition to be inadequate. The definition does not take into account that participants were 'told' to provide untrue answers or the fact that the true answers were known by the assessors. This situation is more comparable to a dramatic performance or acting rather than deception. A more appropriate definition of a lie would include the intent to deceive that is always present in a lie. These participants did not intend to deceive anyone with the 'false' answers, so they cannot be seen as lying.

Furthermore, the study adopts an approach that does not take into account the emotional and contextual elements involved in deception. The consequences of lying or not lying during the study were also incomparable to real life. This reduces the ecological validity of the study and makes the findings difficult to generalise.

The participants were also 'required' to make a motor response in order to select their answer. This adds further complexity to the analysis of the study results and further dents the ecological validity.

One of the main findings was that 'mean response times (seconds) were significantly slower during the lie condition'. Although the stated $P$-value (0.024) shows a statistically significant difference, the actual difference of a tenth of a second (the difference between 2.66 and 2.56 seconds) only equates to about $4 \%$ delay. In clinical terms this does not appear to be significant.

The functional magnetic resonance imaging (fMRI) does provide exciting opportunities for research, but the overall utility of this study appears to be very limited; further research of a higher quality is required in this fascinating but complex field.

To overcome some of the problems with the methodology, the researchers would actually have to deceive the participants regarding the aims of such a study. The British Psychological Society provides extensive guidance regarding the use of deception in research (www.bps.org.uk/the-society/code-of-conduct/ethicalprinciples-for-conducting-research-with-human-participants.cfm).

1 Fullam RS, McKie S, Dolan MC. Psychopathic traits and deception: functional magnetic resonance imaging study. Br J Psychiatry 2009; 194: 229-35.

Aamir Ehjaz, John Howard Centre, East London NHS Foundation Trust, 12 Kenworthy Road, London E9 5TD, UK. Email: aamir@doctors.org.uk

doi: 10.1192/bjp.195.3.270

Authors' reply: Dr Ehjaz appears to have misinterpreted the purpose of our study and his comments suggest a lack of awareness of the extensive literature examining the utility of fMRI for the detection of deception. ${ }^{1-4}$

The primary goal of our study was to examine the influence of psychopathic personality traits on neural responses exhibited during deception. We used a direct replication of a previously published simple deception paradigm developed by Spence et al ${ }^{5}$ and our definition of deception was lifted directly from Spence's work in this area. We have clearly acknowledged in the paper that the work presented needs to be replicated with more sophisticated paradigms, including those with an emotional component. The issues surrounding deception paradigm design are adequately covered in the existing literature.

Dr Ehjaz states that our main findings were the reported reaction time differences between the lie and truth conditions. This is not correct. The key findings lie in the modulation of deception-related blood oxygen level-dependent responses by personality traits. The response time data are reported as a direct replication of Spence et al's $\mathrm{s}^{5}$ finding and indicate increased cognitive load associated with the production of a lie at the same time as withholding a truthful response. In neural terms, a mean response time difference of a tenth of a second is really rather significant. 
1 Simpson JR. Functional MRI lie detection: too good to be true? J Am Acad Psychiatry Law 2008; 36: 491-8.

2 Bles M, Haynes JD. Detecting concealed information using brain-imaging technology. Neurocase 2008; 14: 82-92.

3 Sip KE, Roepstorff A, McGregor W, Frith CD. Detecting deception: the scope and limits. Trends Cogn Sci 2008; 12: 48-53.

4 Spence SA. Playing Devil's advocate: the case against fMRI lie detection. Legal and Criminological Psychology 2008; 13: 11-25.

5 Spence SA, Farrow TD, Herford AE, Wilkinson ID, Zheng Y Woodruff PWR. Behavioural and functional anatomical correlates of deception in humans. Neuroreport 2001; 12: 2849-53.

Rachael S. Fullam, Centre for Forensic Behavioural Science, School of Psychology, Psychiatry and Psychological Medicine, Monash University, Victorian Institute of Forensic Mental Health, Locked Bag 10, Fairfield VIC 3078, Australia. Email: rachael.fullam@forensicare.vic.gov.au; Mairead C. Dolan, Centre for Forensic Behavioural Science, Monash University, Australia

doi: 10.1192/bjp.195.3.270a

\section{Lithium in drinking water and food, and risk of suicide}

Ohgami et al ${ }^{1}$ reported lithium in drinking water $(0.7-59 \mathrm{gm} / \mathrm{l})$ and linked it to suicide rates. However, dietary lithium, which has received scant attention, is found in grains and vegetables, and to some extent animal-derived foods. ${ }^{2}$ Hence, considering only lithium in drinking water may not be enough of a link to suicide rates. Dietary sources of lithium may actually have made the difference rather than just the drinking water. Differences in the prevalence of mood disorders with natural lithium levels acting as a prophylactic have been reported., Jathar et $a l^{3}$ assessed the lithium content of the daily diet $(72.55-154.6 \mu \mathrm{g})$ and biological fluids, and hypothesised lithium to be a natural prophylactic. It will be interesting to see whether dietary and drinking water lithium levels have a direct impact on mood disorder prevalence, which in turn could explain the variation in suicide rates. And what about lithium-containing food cooked in lithium-containing tap water?

1 Ohgami $\mathrm{H}$, Terao $\mathrm{T}$, Shiotsuki I, Ishii $\mathrm{N}$, Iwata N. Lithium levels in drinking water and risk of suicide. Br J Psychiatry 2009; 194: 464-5.

2 Schrauzer GN. Lithium: occurrence, dietary intakes, nutritional essentiality. J Am Coll Nutr 2002; 21: 14-21.

3 Jathar VS, Pendharkar PR, Pandey VK, Raut SJ, Doongaji DR, Bharucha MP, et al. Manic depressive psychosis in India and the possible role of lithium as a natural prophylactic. II - Lithium content of diet and some biological fluids in Indian subjects. J Postgrad Med 1980; 26: 39-44.

4 Doongaji DR, Jathar VS, Satoskar RS. Manic depressive psychosis in India and the possible role of lithium as a natural prophylactic. I - Hypothesis. J Postgrad Med 1980; 26: 34-8.

Geetha Desai, Department of Psychiatry, National Institute of Mental Helath and Neurosciences, Bangalore 560029, India. Email: desaigeetha@gmail.com; Santosh K. Chaturvedi, Department of Psychiatry, National Institute of Mental Helath and Neurosciences, Bangalore, India

doi: 10.1192/bjp.195.3.271

The study by Ohgami et al ${ }^{1}$ raises serious ethical issues related to the interpretation of research findings and, as a consequence, their possible application. While not denying that the findings are interesting and have caused a stir in the lay press and on the internet, we question the methodology and the possible implications if the results are taken seriously.

First, sociological reasons for suicide are important, and changing rates of suicide in many countries are linked to changes such as migration, poverty, relationships and economic issues. The finding that when gender was included in the analysis there was a difference in the significance levels between men and women (with the results being less significant in women) is one such example. Adding lithium to tap water is not going to change these demographic and social factors that contribute to suicide rates, and not having accounted for at least some of these is a major limitation of the study. Second, although we agree with Young ${ }^{2}$ in his commentary that more research is needed to prove or disprove this tantalising idea, it is also important to assess what the impact of different levels of tap-water lithium is going to be on thyroid function, pregnant women and on the unborn fetus. It is also important to assess whether tap-water levels of lithium directly correlate with serum lithium levels in the respective populations. The levels of lithium in body fluids in normal healthy controls have varied from 0.01 to $0.09 \mathrm{meq} / 1$ in one study, ${ }^{3}$ but there are no data about serum lithium levels among individuals attempting suicide. Maybe assessment of serum lithium levels among those with suicidal behaviour can be a place to start. More data are also needed on the role of low-dose lithium in individuals without mood disorders who are at risk of suicide.

Finally, several foods (particularly spices) are known to have relatively high levels of lithium as reported by a study in India several years ago. ${ }^{3}$ This study reported levels as high as $12 \mu \mathrm{g} / \mathrm{g}$ of lithium in tobacco and high levels in crude salt, rock salt and several spices. Maybe, until such time that we are certain about lithium's role in decreasing suicidality in non-psychiatric populations, it might be worth conducting randomised controlled trials with these foods in individuals with suicidal behaviour to see whether low doses of lithium really help.

Let us not throw the lithium out with the tap water yet!

1 Ohgami H, Terao T, Shiotsuki I, Ishii N, Iwata N. Lithium levels in drinking water and risk of suicide. Br J Psychiatry 2009; 194: 464-5.

2 Young $\mathrm{AH}$. Invited commentary on ... Lithium levels in drinking water and risk of suicide. Br J Psychiatry 2009; 194: 466.

3 Jathar VS, Pendharkar PR, Pandey VK, Raut SJ, Doongaji DR, Bharucha MP, et al. Manic depressive psychosis in India and the possible role of lithium as a natural prophylactic. II - Lithium content of diet and some biological fluids in Indian subjects. J Postgrad Med 1980; 26: 39-44.

Prabha S. Chandra, Department of Psychiatry, National Institute of Mental Health and Neurosciences, Bangalore 560029, India. Email: prabhasch@gmail.com; Girish N. Babu, Department of Psychiatry, National Institute of Mental Health and Neurosciences, Bangalore, India

doi: 10.1192/bjp.195.3.271a

Authors' reply: We thank Drs Chandra and Babu for their comments, but we would like to emphasise that we had never recommended the addition of lithium to drinking water supplies ${ }^{1}$ because our findings are preliminary and yet to be conclusive.

First, we agree that sociological factors such as migration, poverty, human relations and economic issues may be associated with suicide rates, and have already admitted such limitations by stating 'other factors such as psychosocial and economic factors were not taken into consideration. ${ }^{1}$ Second, Drs Chandra and Babu state that it is also important to assess side-effects of lithium in tap water on thyroid function, pregnant women and the unborn fetus. Although it seems probable that these low levels of lithium are far below the levels required to produce side-effects, we agree with them. Third, they mention lithium levels in food, also raised by Drs Desai and Chaturvedi. This may be important because dietary lithium intake is estimated not to be a negligible quantity. For example, mean (s.d.) dietary lithium was reported to be: $1560 \mu \mathrm{g} /$ day (980) in China; 1485 (1009) (Tijuana) and 939 (928) (Culiacan) in Mexico; 1090 (324) in Sweden; 1009 (324) in Denmark; 821 (684) (Texas), 650 (740) (New York) and 429 (116) (San Diego) in the USA; 812 (383) in Japan; 406 (383) in Germany; and 348 (290) in Austria. ${ }^{2}$ Therefore, at the next stage, 